\title{
Optimization of Glycerol Concentration and Freezing Rate in the Cryopreservation of Ejaculate From Brown Bear (Ursus arctos)
}

\author{
P de Paz ${ }^{1,2}$, M Alvarez-Rodriguez ${ }^{1,3}$, M Nicolas ${ }^{1,3}$, M Alvarez ${ }^{1,3}$, CA Chamorro ${ }^{1,3}$, S Borragán ${ }^{4}$, F Martinez-Pastor M $^{1,2}$ and L Anel $^{1,3}$ \\ ${ }^{1}$ ITRA-ULE, INDEGSAL; ${ }^{2}$ Molecular Biology; ${ }^{3}$ Animal Reproduction and Obstetrics, University of León, León; ${ }^{4}$ Cabárceno Park, Cantabria, \\ Spain
}

\begin{abstract}
Contents
In order to establish a semen bank for the endangered Cantabrian brown bear, we tested five glycerol concentrations and three freezing rates for electroejaculated semen. Electroejaculation was performed on nine males. Semen was diluted in TES-Tris-Fructose $(20 \%$ egg yolk, 2\% EDTA, 1\% Equex) with $2 \%, 4 \%, 6 \%, 8 \%$ or $10 \%$ glycerol and frozen at $-10,-20$ or $-40{ }^{\circ} \mathrm{C} / \mathrm{min}$. Before and after cryopreservation, samples were analysed for motility (CASA), viability (VIAB) and acrosomal status (flow cytometry). Pre-freezing results showed that glycerol concentration had no significant effect on total motility or progressive motility, but it significantly decreased VCL, ALH, VIAB and acrosomal status $(p<0.05)$. After thawing, sperm motility was higher at extender with $4 \%, 6 \%$ and $8 \%$ glycerol, but only at $4 \%$ and $6 \%$ glycerol for VIAB and acrosomal status. For $4 \%$ and $6 \%$ glycerol, freezing rates did not have significant effects. The curve fitting gave an estimate of the optimal glycerol concentration, with all the optimal values for every parameter between $6 \%$ and $7 \%$ glycerol falling. We propose using $6 \%$ glycerol and a freezing velocity of $-20^{\circ} \mathrm{C} / \mathrm{min}$ for freezing brown bear ejaculated spermatozoa.
\end{abstract}

\section{Introduction}

Specific adaptation of freezing protocols in wild species could improve strategies to establish and manage Genome Resource Banks (GRB). GRBs, in combination with assisted reproductive techniques, can be used to support the conservation of endangered species (Holt 1 and Lloyd 2009). This is the case of the Cantabrian brown bear (Ursus arctos). The species is not catalogued as threatened worldwide (Least Concern, IUCN 2008), because of large populations in Russia, Canada and some regions in Europe. However, the Iberian population (currently limited to Northern Spain) is seriously endangered because of isolation and high vulnerability (Anel et al. 2008) and is considered to be at risk of extinction (Real Decreto 439/1990 of the Spanish law, regulation of the National Catalogue of Endangered Species).

A critical step in the cryopreservation of a sample is the choice of an adequate cryoprotectant and its optimal concentration. Glycerol has been one of the most widely applied cryoprotectant additives for spermatozoa (Watson 1990), being successfully used in mammals (Pegg

2 et al., 2002). With regard to Ursidae, Giant panda (Ailuropoda melanoleuca) spermatozoa have been cryopreserved using 5\% (Spindler et al. 2004) and 6\% (PerezGarnelo et al. 2004) glycerol. Ishikawa et al. (2002) reported using 4.7\% glycerol for freezing ejaculated semen from Hokkaido brown bears (Ursus arctos yeoensis). Okano et al. (2004, 2006a) cryopreserved semen from Japanese black bears (Ursus thibetanus japonicus) at a final glycerol concentration of $8 \%$. However, in other experiments with this species, Okano et al. (2006b) tested different concentrations of glycerol at between $4 \%$ and $12 \%$, to evaluate its effects on semen cryopreservation, obtaining the best results [viability (VIAB) and intact acrosomes] using $4 \%$ and $6 \%$ glycerol. In a preliminary study on brown bear semen (U. arctos), Anel et al. (2010) did not detect any differences among samples cryopreserved using $4 \%$ or $8 \%$ glycerol.

Freezing rate is another relevant aspect in semen cryopreservation. Cells are subjected to different kinds of stress depending on the freezing rate at which they are cooled Muldrew (2008). The optimal freezing rate depends on many factors affecting the osmotic behaviour of the cell, the most important being the cryoprotectant media and the pre-freezing protocol. Thus, an optimal freezing method must define the appropriate combination of these parameters (Woelders et al.1997; Gao and Critser 2000; Fernández-Santos et al. 2006). If cells are cooled too rapidly, water cannot exit from the cell fast enough to maintain a balance of solutes. Conversely, if the cells are cooled too slowly, most of the water inside them exits and this may cause cell injury. The optimal freezing rate would dehydrate cells with minimal impact, while preventing intracellular ice growth (Woods et al. 2004). Studies on bears usually report freezing rates as height above liquid nitrogen (LN), being difficult to compare results. Thus, Okano et al. (2004, 2006a,b) reported freezing Japanese black bear semen by placing straws $6 \mathrm{~cm}$ above LN, not reporting freezing rates. Ishikawa et al. (2002) used a variable height system (30, 4 and $2 \mathrm{~cm}$ above LN, at 2 min intervals) for freezing Hokkaido brown bear sperm. These authors measured the freezing rate provided by that system, being $-9.8^{\circ} \mathrm{C} / \mathrm{min}$ from 4 to $-7.5^{\circ} \mathrm{C}$, and $-46.6^{\circ} \mathrm{C} / \mathrm{min}$ from -7.5 to $-100^{\circ} \mathrm{C}$. Although sperm VIAB was good after thawing, motility was only $21 \%$ compared with $55 \%$ of the pre-freezing value.

In this study, we implemented five different glycerol concentrations $(2 \%, 4 \%, 6 \%, 8 \%$ and $10 \% \mathrm{v} / \mathrm{v})$ and three different freezing rates $\left(-10,-20\right.$ and $\left.-40^{\circ} \mathrm{C} / \mathrm{min}\right)$ to define the optimal values for the species. Moreover, as the factors involved in a successful freezing protocol usually interact, we aimed at seeking the best combination of both factors for freezing brown bear semen.

\section{Materials and Methods}

All the products were obtained from Sigma (Madrid, Spain), except Equex STM Paste (Minitüb, Tiefenbach, Germany).

\begin{tabular}{|l|l|l|l|l|l|l|l|l|l|l|l|l|}
\hline & $\mathbf{R}$ & $\mathbf{D}$ & $\mathbf{A}$ & & $\mathbf{1}$ & $\mathbf{8}$ & $\mathbf{0}$ & $\mathbf{8}$ & $\mathbf{D}$ & Dispatch: 7.5.11 & Journal: RDA & CE: Vinoth \\
\cline { 1 - 3 } \\
\hline
\end{tabular}




\section{Animals and sample collection}

Fifteen ejaculates from nine brown bears were obtained by electroejaculation during the breeding season (late April to early July, 2008-2009). Animal age was estimated, so all the captured males were adults (between 7 and 20 years). The animals were housed in a half-freedom regime in Cabárceno Park (Cantabria, Spain; $43^{\circ} 21^{\prime} \mathrm{N}, 3^{\circ} 50^{\prime} \mathrm{W}$, altitude: $142 \mathrm{~m}$ ) and fed with a diet based on chicken meat, bread and fruits; feeding followed the hierarchical order, with the dominant bears taking most food. Animal manipulations were performed in accordance with Spanish Animal Protection Regulation RD1201/2005, which conforms to European Union Regulation 2003/65.

The males were immobilized by teleanaesthesia, using zolazepam $\mathrm{HCl}$, tiletamine $\mathrm{HCl}\left(\right.$ Zoletil100 $^{\circledR}$; Virbac, Carros, France) $7 \mathrm{mg} / \mathrm{kg}$, and ketamine (Imalgene $1000^{\circledR}$; Rhone-Mérieux, Lyon, France) $2 \mathrm{mg} / \mathrm{kg}$. After immobilization, they were weighed and monitored (pulse, oxygen saturation and respiration). Prior to electroejaculation, the prepucial area was shaved and washed with sterile physiological saline, and the rectum was emptied of faeces. The bladder was catheterized during semen collection to prevent urine contamination. Electroejaculation was carried out with a PT Electronics $^{\circledR}$ electroejaculator (PT Electronics, Boring, OR, USA). The transrectal probe was $320 \mathrm{~mm}$ long with a diameter of $26 \mathrm{~mm}$. Electric stimuli were given until ejaculation (10 $\mathrm{V}$ and $250 \mathrm{~mA}$, on average). The average duration of the procedure of electroejaculation is $10^{\prime} 34^{\prime \prime}$ $\left(5^{\prime} 49^{\prime \prime}\right.$ from the start of the process until ejaculation begins $+4^{\prime} 45^{\prime \prime}$ of ejaculation). The ejaculates were collected as isolated fractions in graduated glass tubes to prevent urine contamination or low cellular concentration. Fractions of reduced concentration $\left(<200^{\circ} \times 10^{6} \mathrm{cell} / \mathrm{ml}\right)$, low motility $(<50 \%)$ or urine contaminated ( $>80 \mathrm{mg}$ urea/dl) were rejected as explained in the following paragraphs. Two ejaculates were obtained by bear (one per year). Of the 18 ejaculates obtained from nine bears, three have been eliminated for failing to provide the minimum quality. All valid fractions of the same ejaculate were mixed (fifteen ejaculates in experiments).

\section{Experimental design}

The selected ejaculates were centrifuged at $600 \times g$ for 6 min for reaching an adequate sperm concentration and cleaning urine-contaminated samples (Nicolas et al. 2011). The supernatant was discarded, and each pellet was diluted with an equal volume of TTF cryopreservation extender (TES-Tris-Fructose, supplemented with $4 \%$ glycerol, $20 \%$ egg yolk, $2 \%$ EDTA and $1 \%$ Equex STM paste; $300 \mathrm{mOsm} / \mathrm{kg}, \mathrm{pH} 7.1$ ) at room temperature. Tubes with the diluted semen (at $2 \%$ glycerol) were put in glasses containing $100 \mathrm{ml}$ of water at room temperature and transferred to refrigerated containers at $5^{\circ} \mathrm{C}$, so the temperature decreased slowly to $5^{\circ} \mathrm{C}(70-80 \mathrm{~min})$. Then, the samples were split among five tubes, and each tube was diluted $1: 1$ with an extender containing $2 \%, 6 \%, 10 \%, 14 \%$ or $18 \%$ glycerol to achieve the final glycerol concentrations
$(2 \%, 4 \%, 6 \%, 8 \%$ and $10 \%$, respectively). Final sperm concentration $\left(100 \times 10^{6} \mathrm{cell} / \mathrm{ml}\right)$ was achieved by adding the appropriate volume of the extender at the same glycerol concentration.

An equilibration period of $1 \mathrm{~h}$ at $5^{\circ} \mathrm{C}$ was applied, during which the semen was packaged into $0.25-\mathrm{ml}$ plastic straws. The straws were frozen in a programmable biofreezer (Kryo 560-16 Planer $^{\mathrm{TM}}$, Middlesex, UK) at each of the three ramps tested $\left(-10,-20\right.$ or $\left.-40^{\circ} \mathrm{C} / \mathrm{min}\right)$, down to $-100^{\circ} \mathrm{C}$, and then transferred to $\mathrm{LN}$ containers. The cryopreserved samples were stored in LN for a minimum of 1 week. The straws were thawed by plunging them into water at $65^{\circ} \mathrm{C}$ for $6 \mathrm{~s}$. Sperm quality parameters were evaluated before freezing and after thawing at room temperature.

\section{Semen evaluation}

Immediately after collection, for each fraction, volume was recorded, osmolality was measured using a cryoscopic osmometer Osmomat-030 (Gonotec ${ }^{\mathrm{TM}}$, Berlin, Germany) and the $\mathrm{pH}$ value was determined by a CG $837 \mathrm{pH}$ meter (Schott Instruments, Main, Germany). Sperm concentration was assessed (Bürker hemocytometer, Marienfeld $\mathrm{GmbH}$, Marienfeld, Germany) using CASA (ISAS, Integrated Semen Analyser System; 3 Proiser, Valencia, Spain). Subjective total motility was assessed with a phase contrast microscope $(\times 100)$ and urospermia was evaluated by means of a Merckgnost Urea Rapid Screening test (Merck, Barcelona, Spain).

The motility and kinematics parameters were evaluated using a computer-assisted semen motility analysis system (ISAS, Integrated Semen Analyser System; Proiser). The standard settings of the CASA used correspond to the values of dog spermatozoa defined by ISAS. The settings used to define progressive motility are specific to bears and are defined by our previous experience (Anel et al. 2010). Samples were diluted (10$20 \times 10^{6}$ cells $/ \mathrm{ml}$ ) in a buffer (HEPES 20, $197 \mathrm{~mm} \mathrm{NaCl}$, $2.5 \mathrm{~mm} \mathrm{KOH}, 10 \mathrm{~mm}$ glucose; $\mathrm{pH} 7 ; 300 \mathrm{mOsm} / \mathrm{kg}$ ) with $1 \%$ egg yolk, and warmed on a $37.5^{\circ} \mathrm{C}$ plate for $5 \mathrm{~min}$. Then, a $5 \mu \mathrm{l}$ sperm sample was placed in a Makler counting cell chamber $(10 \mu \mathrm{m}$ depth; Sefi Medical Instruments, Haifa, Israel) and examined using a negative phase contrast microscope $(\times 10)$ with a warmed stage $\left(38^{\circ} \mathrm{C}\right)$. The standard settings were 25 frames/s, 5-80 $\mu \mathrm{m}^{2}$ for head area and curvilinear velocity $>10 \mu \mathrm{m} / \mathrm{s}$ to classify a spermatozoon as motile. At least five fields or 200 spermatozoa were saved and analysed afterwards. Reported parameters were total motility (TM, \%; spermatozoa with VCL > $10 \mu \mathrm{m} / \mathrm{s}$ ), progressive motility (PM, \%; spermatozoa were considered progressive if VCL > 25 and STR > 80), average path velocity (VAP, $\mu \mathrm{m} / \mathrm{s}$ ), curvilinear velocity (VCL, $\mu \mathrm{m} / \mathrm{s})$, straight-line velocity $(\mu \mathrm{m} / \mathrm{s})$, linearity $(\%)$ and amplitude of lateral head displacement (ALH, $\mu \mathrm{m})$.

Sperm VIAB and acrosomal status were assessed using the double stain PNA-FITC/PI and flow cytometry. Stock solutions of the fluorochromes were prepared in PBS at $1 \mu \mathrm{g} / \mathrm{ml}$ PNA-FITC and $24 \mu \mathrm{M}$ PI. Sperm samples were diluted with PBS down to $5 \times 10^{6}$ spermatozoa $/ \mathrm{ml}$ in polypropylene tubes $(300 \mu \mathrm{l} /$ tube), adding $2.5 \mu \mathrm{l} \mathrm{PI}$ and $2.5 \mu \mathrm{l}$ PNA-FITC to the diluted 
samples. PNA is a lectin from the peanut plant that binds to beta-galactose moieties associated with the outer acrosomal membrane of fixed spermatozoa, indicating acrosome-damaged cells. The flow cytometry analysis yielded the percentage of viable spermatozoa with intact acrosomes (PI- and PNA-, named VIAB) and the percentage of those with damaged acrosomes (PNA + , named dACR).

Flow cytometry evaluations were carried out using a FACScalibur flow cytometer (Becton Dickinson BioSciences, San Jose, CA, USA), equipped with standard optics and an argon-ion laser, tuned at $488 \mathrm{~nm}$ and running at $200 \mathrm{~mW}$. Calibration was carried out periodically using standard beads (Calibrites; Becton Dickinson). Data corresponding to the red (FL3 photodetector) and green fluorescence (FL1 photodetector) of acquired particles were recorded. In all cases, we assessed 10000 events per sample, with a flow rate of 200 cells/s.

\section{Statistical analysis}

Statistical analysis was performed in the $\mathrm{R}$ statistical 4 environment ( $\mathrm{R}$ Development Core Team). Results are shown as means and standard errors, unless otherwise stated. Analyses of the pre-freezing data (only glycerol effects) and post-thawing data (glycerol and freezing rate effects) were carried out using linear mixed-effects models. Models were built with glycerol, freezing rate and their interaction as fixed effects (for pre-freezing data, only glycerol), and sample (with interactions) in the random part of the model. Significant fixed effects were further analysed using multiple comparisons of means with Tukey contrasts; when interactions between glycerol and the freezing rate were significant, these factors were assessed separately by grouping the data by the other factor.
As we expected to find an optimal concentration of glycerol within the range tried, we tested whether the parameters could fit a quadratic linear model, yielding a theoretical maximum for a given glycerol concentration. This test was carried out using linear models with glycerol as factor.

We calculated post-thawing recovery rates as a way of assessing sample freezability in each glycerol/freezing rate combination. These rates were calculated by dividing the post-thawing value of each parameter by its prefreezing value and multiplying by 100 .

\section{Results}

The pre-freezing evaluation of the samples showed some differences among glycerol concentrations (Fig. 1). The glycerol concentration did not have a significant effect on total or progressive motility, but it did affect VCL, ALH, VIAB and dACR $(p<0.05)$. Increasing the glycerol concentration from $2 \%$ to $10 \%$ in the equilibration phase caused the kinematic parameters VCL and ALH to drop by almost 25\%. Glycerol also affected sperm VIAB and acrosomal status, and 10\% glycerol caused a significant decrease in VIAB in comparison with $6 \%$ glycerol.

After thawing (Fig. 2), the effect of glycerol was highly significant for the motility parameters $(\mathrm{p}<0.001)$. In general, the lower concentration of $2 \%$ yielded lower motility values $(\mathrm{p}<0.05)$. The $6 \%$ concentration gave higher average results for motility, being significantly higher than $2 \%$ and $10 \%$. Curve fitting analyses (Fig. 3) showed that the data for all motility parameters could be fitted to a quadratic curve, showing a maximum of between $6 \%$ and $7 \%$ glycerol. Also, VIAB was fitted to a quadratic linear model (maximum at 6\%), while dACR showed a minimum value at $2.9 \%$ glycerol.
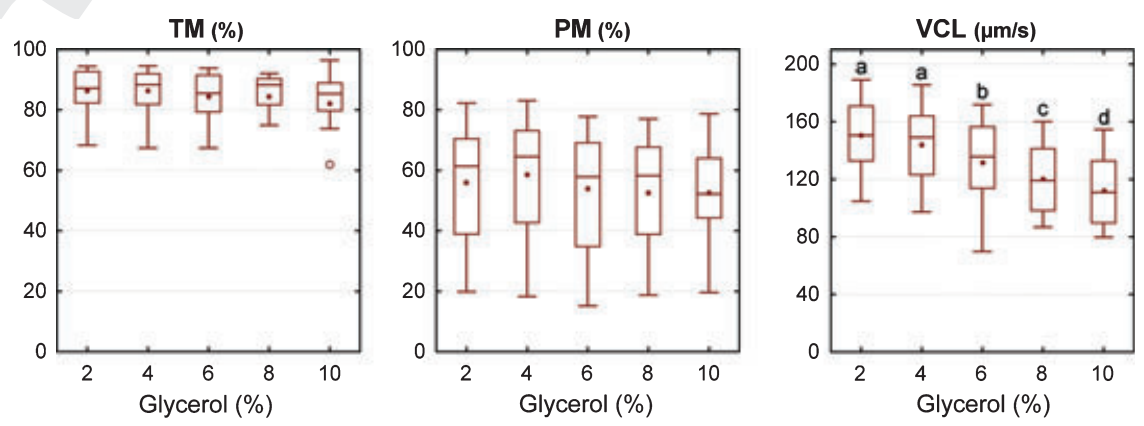

8 Fig. 1. Boxplot of pre-freezing sperm parameters for the five glycerol concentrations. TM, total motility; PM, progressive motility; VCL, curvilinear velocity; ALH, mean amplitude of the lateral head displacement; VIAB, viable spermatozoa with intact acrosomes (PNA-/PI-), dACR: damaged acrosomes (PNA + ). (-) Median and (•) Mean; $(\square)$ interquartile range; $(工)$ non-outlier range and (O) outliers. Different letters indicate that means differ between glycerol concentrations $(\mathrm{p}<0.05)$
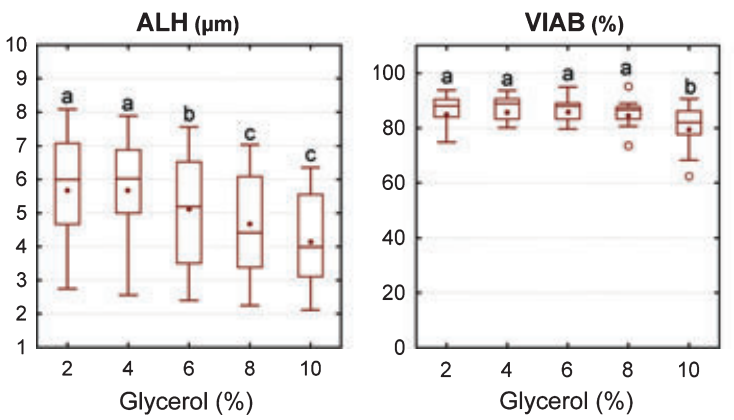

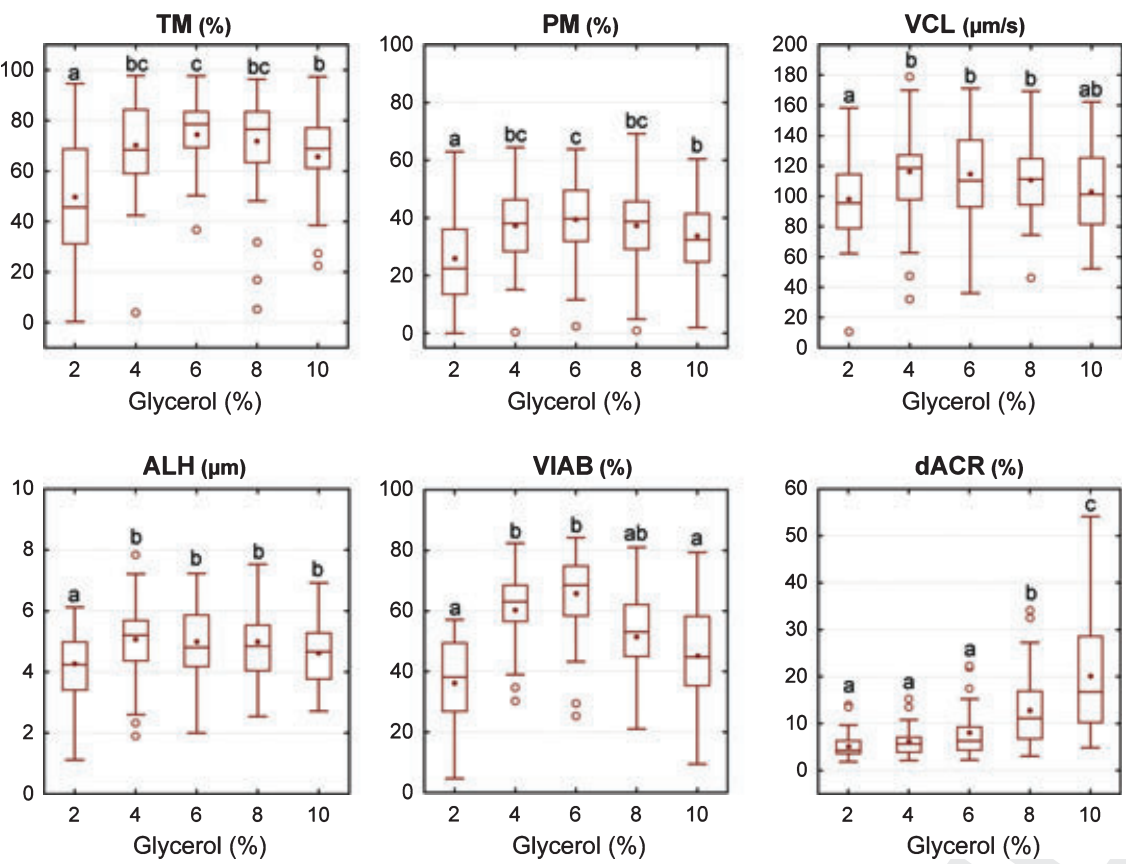

Fig. 2. Boxplot of post-thaw sperm parameters for the five glycerol concentrations. TM, total motility; PM, progressive motility; VCL, curvilinear velocity; ALH, mean amplitude of the lateral head displacement; VIAB, viable spermatozoa with intact acrosomes (PNA-/PI-), dACR, damaged acrosomes (PNA +). (-) Median; (•) Mean; ( $\square$ ) interquartile range; (I) non-outlier range and (O) outliers. Different letters indicate that means differ between glycerol concentrations $(\mathrm{p}<0.05)$
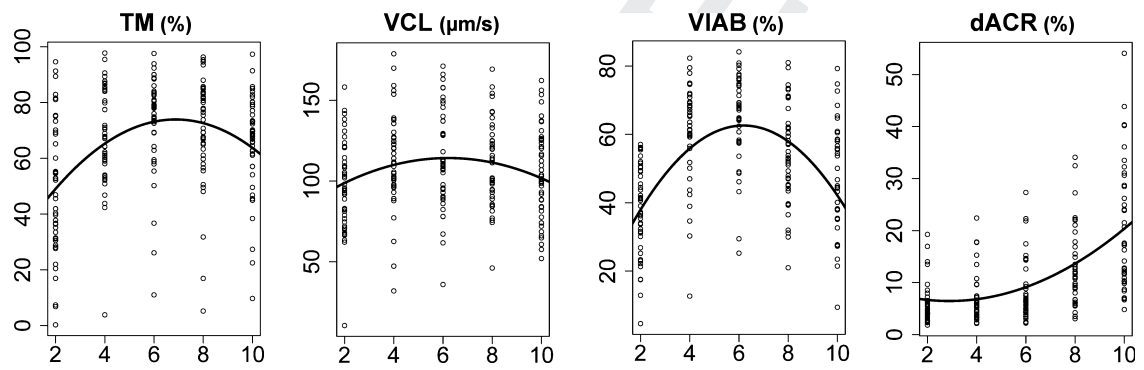

Fig. 3. Curve fitting for total motility (TM), curvilinear velocity (VCL), viable spermatozoa with intact acrosomes (VIAB) and spermatozoa with damaged acrosomes (dACR), with glycerol concentrations (quadratic model). The plots show data points with the model curve overplotted. The maximum values for each parameter corresponded to glycerol concentrations of $6.88 \%$ (TM), $6.21 \%$ (VCL), 6.19\% (VIAB), and a minimum value for dACR at $2.9 \%$ glycerol

In contrast to the clear effects of glycerol concentration, the freezing rate had little effect on post-thawing motility (Fig. 4). Only $-10^{\circ} \mathrm{C} / \mathrm{min}$ yielded significantly lower results on progressive motility in comparison with $-20^{\circ} \mathrm{C} / \mathrm{min}$.

For VIAB and dACR, the effect of glycerol depended on the freezing rate used as can be seen in Table 1. Glycerol at $2 \%$ rendered the lowest VIAB values for the three freezing ramps, whereas $6 \%$ glycerol showed the highest values, although these differences were not significant. Using $8 \%$ or $10 \%$ glycerol, $-10^{\circ} \mathrm{C} / \mathrm{min}$ yielded significantly higher VIAB than $-40^{\circ} \mathrm{C} / \mathrm{min}$. The interaction between glycerol and the freezing rate was clearly evident in the dACR parameter, where the increasingly lower performance of the highest concentrations, especially $10 \%$, when the freezing velocity is increasing can be observed. Thus, for $2 \%$ and $4 \%$ glycerol, we observed greater damage to the acrosome at $-10^{\circ} \mathrm{C} / \mathrm{min}$ than at $-20^{\circ} \mathrm{C} / \mathrm{min}(\mathrm{p}<0.05)$, whereas for $8 \%$ and $10 \%-40{ }^{\circ} \mathrm{C} / \mathrm{min}$ yielded higher acrosomal damage. In all cases, $8 \%$ and $10 \%$ glycerol rendered significantly higher percentages of dACR than the other glycerol concentrations.
Analysis of recovery rates (Table 2) showed that only glycerol had an effect on these rates, thus samples frozen with $2 \%$ glycerol had poorer freezability in terms of maintaining motility parameters or cell VIAB during the freezing/thawing process. In fact, freezing with $6 \%$ glycerol yielded the higher mean freezability in motility and VIAB, although the recovery rates of $4 \%$ and $8 \%$ were not significantly different in any case. Only freezability for dACR showed an interaction between the effects of glycerol and the freezing speed. The recovery rates of $\mathrm{dACR}$ were higher (increased acrosomal damage during freezing) with glycerol at $8 \%$ and $10 \%$ only when the freezing ramp was $-40^{\circ} \mathrm{C} / \mathrm{min}$. In general, for any freezing ramp, the recovery rates of dACR were higher with glycerol at $8 \%$ and $10 \%$, although these differences did not reach significance for -10 and $-20{ }^{\circ} \mathrm{C} / \mathrm{min}$.

\section{Discussion}

We have evaluated five glycerol concentrations and three freezing ramps for improving the cryopreservation of brown bear semen. Our results seek to optimize the 

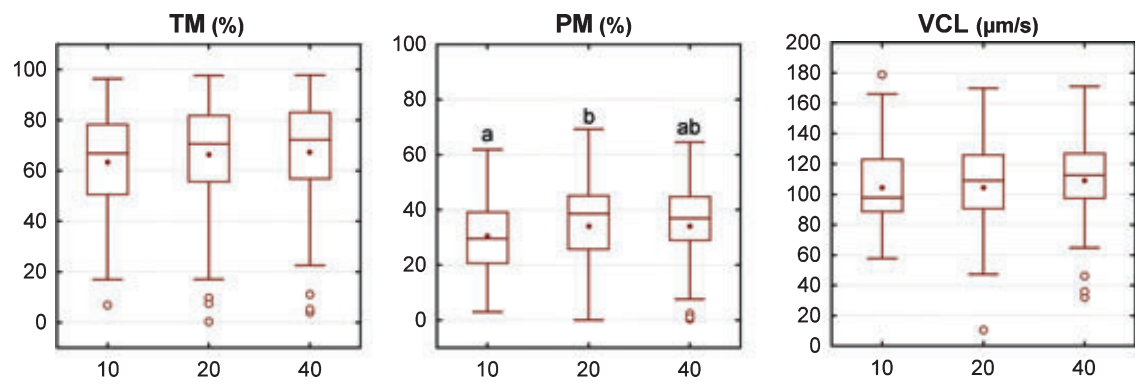

Fig. 4. Boxplot of post-thaw sperm parameters for the three freezing rates $(-10 ;-20$; $\left.-40^{\circ} \mathrm{C} / \mathrm{min}\right)$. TM, total motility; $\mathrm{PM}$, progressive motility; VCL, curvilinear velocity; ALH, mean amplitude of the lateral head displacement; VIAB, viable spermatozoa with intact acrosomes (PNA-/PI-), dACR, damaged acrosomes (PNA +). (-) Median; (•) Mean; $(\square)$ interquartile range; (工) non-outlier range and (O) outliers. Different letters indicate that means differ between freezing ramps $(\mathrm{p}<0.05)$
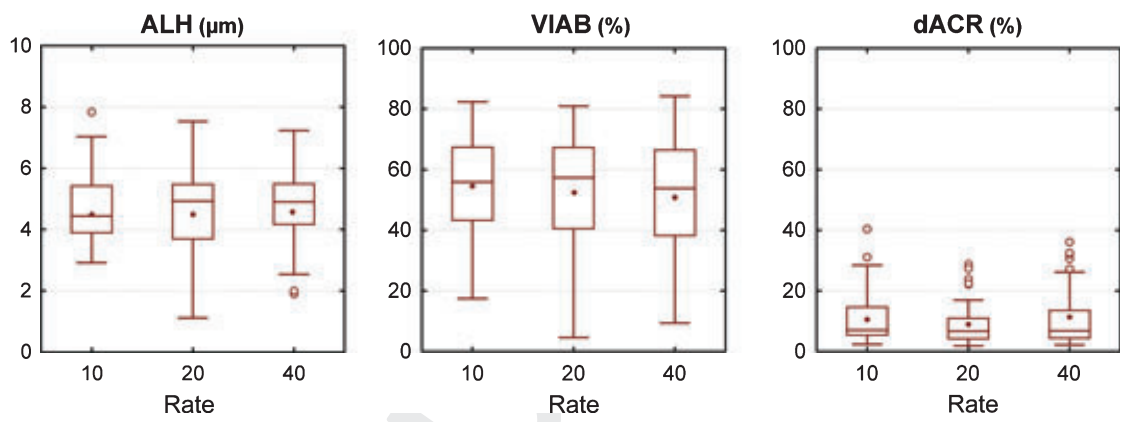

Table 1. Effects of interactions between glycerol concentration (GLY) and the freezing rates (RATE) on post-thaw spermatozoa quality (Means \pm SEM): viability (VIAB, PI-/PNA-) and damaged acrosomes (dACR, PNA +)

\begin{tabular}{cccc}
\hline GLY & RATE & VIAB & dACR \\
\hline 2 & 10 & $35.5 \pm 3.5^{\mathrm{A}}$ & $6.8 \pm 0.6^{\mathrm{Aa}}$ \\
2 & 20 & $33.9 \pm 4.4^{\mathrm{A}}$ & $5.6 \pm 0.6^{\mathrm{Aab}}$ \\
2 & $42.3 \pm 2.8^{\mathrm{A}}$ & $4.7 \pm 0.3^{\mathrm{Ab}}$ \\
4 & 10 & $58.9 \pm 3.9^{\mathrm{BC}}$ & $8.4 \pm 0.7^{\mathrm{Aa}}$ \\
4 & 20 & $60.3 \pm 4.1^{\mathrm{BD}}$ & $6.3 \pm 0.6^{\mathrm{Ab}}$ \\
4 & 40 & $66.7 \pm 2.1^{\mathrm{B}}$ & $5.6 \pm 0.4^{\mathrm{Ab}}$ \\
6 & 10 & $64.5 \pm 3.8^{\mathrm{B}}$ & $8.3 \pm 0.7^{\mathrm{A}}$ \\
6 & 20 & $65.8 \pm 3.8^{\mathrm{B}}$ & $7.9 \pm 0.8^{\mathrm{A}}$ \\
6 & 40 & $58.1 \pm 3.1^{\mathrm{BCa}}$ & $7.9 \pm 0.8^{\mathrm{A}}$ \\
8 & 10 & $54.4 \pm 3.8^{\mathrm{CDab}}$ & $11.9 \pm 0.8^{\mathrm{Bab}}$ \\
8 & 20 & $49.5 \pm 3.8^{\mathrm{Ab}}$ & $14.6 \pm 1.1^{\mathrm{Ba}}$ \\
8 & 40 & $51.1 \pm 3.8^{\mathrm{Ca}}$ & $18.5 \pm 1.6^{\mathrm{Ca}}$ \\
10 & 10 & $50.8 \pm 3.5^{\mathrm{Ca}}$ & $16.4 \pm 1.6^{\mathrm{Ba}}$ \\
10 & 20 & $39.8 \pm 4.1^{\mathrm{Ab}}$ & $23.9 \pm 1.7^{\mathrm{Cb}}$ \\
10 & 40 &
\end{tabular}

Capital letters indicate significant differences among glycerol concentrations fo each freezing rate $(\mathrm{p}<0.05)$ and lower-case letters indicate significant differences among freezing ramps for each glycerol concentration $(p<0.05)$.

protocol for spermatozoa cryopreservation of this species tested in previous studies (Okano et al. 2004, 2006a,b; Anel et al. 2010).

One of the objectives of this study was to analyse the differential effect of extreme glycerol concentrations $(2 \%$ and $10 \%)$, in comparison with the optimal range of 4-6\% suggested by other authors (Okano et al. 2006b). Cryoprotectants must be used balancing their cryoprotective action with their toxicity (Pegg 2002). Previous studies in wildlife by our group suggested that red deer spermatozoa might tolerate a wide range of glycerol concentrations (Martinez-Pastor et al. (2006). Pukazhenthi et al. (2007) reported that Eld's deer showed good acrosomal resistance, whereas cheetah or blackfooted ferret showed high acrosomal sensitivity to the freezing/thawing process. Our pre-freezing results
Table 2. Recovery rates [(Post-thaw/pre-freeze value $) \times 100]$ of the samples cryopreserved with the five glycerol concentrations (GLY) and the three freezing rates (RATE), showed as mean \pm SEM

\begin{tabular}{|c|c|c|c|c|c|}
\hline & $\mathrm{TM}$ & PM & VCL & $\mathrm{ALH}$ & VIAB \\
\hline \multicolumn{6}{|c|}{ GLY* } \\
\hline 2 & $56.1 \pm 4.3^{\mathrm{a}}$ & $52.1 \pm 4.9^{\mathrm{a}}$ & $66.8 \pm 3.3^{\mathrm{a}}$ & $81.6 \pm 5.5^{\mathrm{a}}$ & $39.1 \pm 2.3^{\mathrm{a}}$ \\
\hline 4 & $79.9 \pm 3.3^{\mathrm{b}}$ & $72.4 \pm 6.2^{\mathrm{b}}$ & $81.4 \pm 3.9^{b}$ & $97.1 \pm 6.9^{\mathrm{a}}$ & $67.6 \pm 2.7^{\mathrm{b}}$ \\
\hline 6 & $87.8 \pm 3.5^{b}$ & $85.3 \pm 7.5^{b}$ & $86.5 \pm 3.5^{\mathrm{bc}}$ & $105.4 \pm 6.4^{\mathrm{b}}$ & $77.4 \pm 1.9^{\mathrm{c}}$ \\
\hline 8 & $83.7 \pm 3.4^{\mathrm{b}}$ & $75.5 \pm 5.7^{\mathrm{b}}$ & $92.4 \pm 3.9^{\mathrm{c}}$ & $117.8 \pm 7.7^{\mathrm{b}}$ & $66.8 \pm 16.5^{\mathrm{bd}}$ \\
\hline 10 & $77.4 \pm 3.6^{\mathrm{b}}$ & $63.8 \pm 4.1^{\mathrm{ab}}$ & $93.5 \pm 3.6^{\mathrm{c}}$ & $116.9 \pm 6.2^{\mathrm{b}}$ & $55.3 \pm 3.4^{\mathrm{d}}$ \\
\hline \multicolumn{6}{|c|}{ Rate* } \\
\hline 10 & $74.1 \pm 2.9$ & $64.4 \pm 4.3$ & $82.2 \pm 3.3$ & $102.6 \pm 5.6$ & $63.4 \pm 2.7$ \\
\hline 20 & $78.7 \pm 3.3$ & $77.8 \pm 5.4$ & $84.9 \pm 3.2$ & $104.8 \pm 5.6$ & $63.1 \pm 2.7$ \\
\hline 40 & $78.3 \pm 2.9$ & $67.6 \pm 4.1$ & $85.4 \pm 2.7$ & $104.2 \pm 4.8$ & $57.6 \pm 2.4$ \\
\hline
\end{tabular}

*There were no interactions between the GLY and RATE factors.

TM, total motility; PM, progressive motility; VCL, curvilinear velocity; ALH, amplitude of lateral head displacement; VIAB, viable spermatozoa with intact acrosomes.

Lower-case letters indicate significant differences among glycerol concentrations $(\mathrm{p}<0.05)$, and capital letters indicate significant differences among freezing rates $(\mathrm{p}<0.05)$

showed a damaging effect of $10 \%$ glycerol on acrosomes and plasmalemma, possibly because of osmotic effects, which are also reflected in diminished kinetic parameters. Although glycerol protects the spermatozoa during the freezing/thawing process, the osmotic stress associated with glycerol addition could be the cause of the decreasing quality in the pre-freezing analysis for the highest glycerol concentrations (Gao et al. 1995). Province et al. (1984) reported that $6 \%$ glycerol, not $3 \%$, depressed sperm motility during long storage of canine spermatozoa at $5^{\circ} \mathrm{C}$, whereas this effect was not observed for equine semen. These results resemble ours in bear, because VCL and ALH were higher in 2\% glycerol, decreasing when the glycerol concentration was increased, and showing some kind of depressing effect on the motility. Moreover, we have to take into account that our freezing protocol included two dilution steps involving increasing the glycerol concentration. The first 


\begin{tabular}{lccccc}
\hline & \multicolumn{5}{c}{ GLY } \\
\cline { 2 - 5 } RATE & 2 & 4 & 6 & 8 & 10 \\
\hline 10 & $417.7 \pm 50.7^{\mathrm{A}}$ & $389.6 \pm 77.1^{\mathrm{A}}$ & $442.2 \pm 87.4^{\mathrm{A}}$ & $447.2 \pm 71.2^{\mathrm{Bab}}$ & $593.6 \pm 116.9^{\mathrm{Ca}} \mathbf{7}$ \\
20 & $312.3 \pm 56.6^{\mathrm{A}}$ & $305.2 \pm 69.4^{\mathrm{A}}$ & $384.1 \pm 77.7^{\mathrm{AB}}$ & $476.2 \pm 128.1^{\mathrm{BCa}}$ & $521.4 \pm 101.9^{\mathrm{Ca}}$ \\
40 & $311.2 \pm 51.3^{\mathrm{A}}$ & $327.8 \pm 64.8^{\mathrm{A}}$ & $458.9 \pm 116.8^{\mathrm{A}}$ & $687.4 \pm 170.3^{\mathrm{Bb}}$ & $919.2 \pm 181.2^{\mathrm{Cb}}$ \\
\hline
\end{tabular}

Table 3. Recovery rates* for damaged acrosomes (dACR, PNA + ) of the samples cryopreserved with the five glycerol concentrations (GLY) and the three freezing rates

$*($ Post-thaw/pre-freeze value $) \times 100$.

Capital letters indicate significant differences among glycerol concentrations $(\mathrm{p}<0.05)$, and lower-case letters indicate significant differences among freezing ramps $(\mathrm{p}<0.05)$.

one occurred at ambient temperature after centrifugation of the samples, achieving a $2 \%$ glycerol concentration. The second step occurred after cooling at $5^{\circ} \mathrm{C}$, achieving the final glycerol concentration. Therefore, samples with $2 \%$ glycerol actually avoided a second osmotic challenge when adding higher concentrations of glycerol. However, as equilibration only lasted for approximately $1 \mathrm{~h}$, it is possible that glycerol-induced irreversible effects may not have taken place yet, except for the highest concentration of $10 \%$. This potential damaging effect of glycerol at $5^{\circ} \mathrm{C}$ should be taken into account in future studies, especially dealing with longer equilibration times or extended cooled storage; this may be necessary because the sampling area in wildlife is often far from the laboratories where the ejaculates are processed. The addition of glycerol in various steps has been applied by Ishikawa et al. (2002). These authors froze semen from Hokkaido brown bears using a final glycerol concentration of $4.7 \%$ (adding extender with $14 \%$ glycerol in various steps every 20 min during cooling) and using a multi-step freezing procedure. They obtained a post-thaw mean total motility of above $35 \%$ $(90 \%$ in fresh spermatozoa), much lower than those obtained in the present study.

Despite the good pre-freezing results achieved by the samples with $2 \%$ glycerol, post-thawing analysis showed that its cryoprotecting ability was too low. The effects of cryo-injuries on spermatozoa are complex and may result from two main factors: osmotic stress and intracellular ice formation. Cells cannot survive these impacts without special measures of protection (Holt (2000a). As glycerol prevents the formation of intracellular ice, it would be logical that $2 \%$ glycerol showed better results combined with the slower freezing rate $\left(-10^{\circ} \mathrm{C} / \mathrm{min}\right)$, as a slow freezing rate allows cells to achieve greater dehydration before reaching the ice nucleation temperature, thus reducing the risk of intracellular ice formation, therefore compensating the lack of cryoprotectant. However, our results showed that the $-40^{\circ} \mathrm{C} / \mathrm{min}$ freezing rate improved the freezability of samples frozen in $2 \%$ glycerol. We hypothesize that with a low glycerol concentration, damage resulting from osmotic stress or salt precipitation would be more important than damage from intracellular ice Muldrew (2008), thus achieving better results from faster freezing ramps.

Conversely, results obtained with $10 \%$ glycerol were worsened by fast freezing $\left(-40^{\circ} \mathrm{C} / \mathrm{min}\right)$. As the observed effects were increasing membrane and acrosomal damage, fast freezing may have created the conditions for enhanced cellular osmotic stress during the fast thawing procedure (Curry and Watson 1994; Woods et al. 2004). Another possibility is that high glycerol concentrations could have caused sub-lethal damage during the equilibration phase, not observed in the pre-freezing analysis, but which could have prevented a subpopulation of spermatozoa from enduring the freezing/thawing process, especially when applying a faster freezing rate (greater chance for intracellular ice formation).

Curve fitting gave an estimate of the optimal glycerol concentration, and all of the optimal values for every parameter were between $6 \%$ and $7 \%$ glycerol. Nevertheless, we observed that semen motility does not vary significantly in the range of $4-8 \%$ for the three freezing rates analysed, coinciding with those observed by Okano et al. (2006b) and Anel et al. (2008).

Nevertheless, although $8 \%$ glycerol was found to render good results regarding motility, this glycerol concentration induces significant damage to the acrosome, and therefore, it seems that osmotic stress, a likely explanation for the acrosomal damage, exceeds other cryoprotective benefits. The optimal glycerol concentration might vary depending on the experimental protocol and species. In giant panda ( $A$. melanoleuca), Spindler et al. (2004) used 5\% glycerol (added before cooling), obtaining a total motility of $55 \%$ after thawing (from above $70 \%$ in fresh spermatozoa), which is more similar to our results. In fact, these authors tested a fast freezing rate $\left(-40^{\circ} \mathrm{C}\right.$ during the first minute and $-100^{\circ} \mathrm{C} / \mathrm{min}$ afterwards), reporting that neither acrosomal status nor capacitation status was affected. Thus, if glycerol concentration is almost optimal, the freezing rate might be a secondary factor in post-thawing quality.

Nevertheless, we have to take into account that we have used only one thawing rate in our experiment. Because a successful cryopreservation protocol depends as much on the thawing method as on the freezing method (Hammadeh et al. 2001), we cannot discard that different results could appear with a different thawing rate.

In any case, it must be highlighted that our curve fitting analyses did not consider the male factor. Thus, future studies should be aimed at analysing within and between male variability regarding glycerol tolerance. In fact, customized freezing protocols are beginning to be considered in domestic species, in order to cryopreserve spermatozoa from valuable males whose freezability differs from the general population, or in species with a high male-to-male variability in terms of sperm freezability (Chaveiro et al. 2006; Loomis and Graham 2008). Male-to-male variability in wildlife is possibly higher than in most farm animals, and therefore, specific 
studies are needed to establish standardized protocols for those species (Holt 2000b; Esteso et al. 2006; Zee et al. 2009). Therefore, the study of such variability and the adjustment of protocols to individual males must not be forgotten in the search for adequate cryopreservation variables for each species.

In conclusion, the optimal glycerol concentration for freezing brown bear spermatozoa obtained by electroejaculation was between $4 \%$ and $8 \%$. Concentrations outside that range are either not enough to protect spermatozoa in the freezing/thawing process $(2 \%)$ or toxic $(10 \%)$. Freezing ramps in the range studied here $\left(-10\right.$ to $\left.-40^{\circ} \mathrm{C} / \mathrm{min}\right)$ might be of lesser importance for the outcome of sperm cryopreservation if glycerol is used within the aforementioned optimal range, but the rate of $-10^{\circ} \mathrm{C} / \mathrm{min}$ have negative results. Future studies should refine these results considering male-to-male variability in the response to freezing variables, in order to define the most adequate protocols for cryopreserving brown bear electroejaculated spermatozoa. We therefore propose a glycerol concentration of $6 \%$ glycerol and a freezing speed of $-20^{\circ} \mathrm{C} / \mathrm{min}$ for freezing brown bear spermatozoa.

\section{Acknowledgements}

The authors thank M. A. Marañon and other keepers of Cabárceno Park (Cantabria, Spain) for their help in managing bears; and to S. Gomez-Alves, M. Mata, E. Anel and F. Martínez for their help in the acquisition and analysis of the samples. This work was supported in part by CICYT (CGL 2007-63748/BOS) and CANTUR S.A. Felipe Martínez-Pastor was supported by the Ramon y Cajal programme (Spanish Ministry of Education and Science).

\section{Conflict of interest}

Xxxxxxxxxxxxxx.

\section{Author contributions}

$\mathrm{P}$ de Paz contributed for research design, acquisition and analysis of data, and to drafting the paper. M Álvarez-Rodríguez contributed for acquisition and analysis of data. M Nicolas contributed for acquisition and analysis of data. M Álvarez contributed for reseach design, the acquisition and analysis of data. C Chamorro contributed for acquisition and analysis of data. S Borragan contributed for acquisition and analysis of data. F Martínez-Pastor contributed for acquisition and analysis of data. L Anel contributed for reseach design, acquisition and analysis of data, and to drafting the paper.

\section{References}

Anel L, Álvarez M, Martinez-Pastor F, Gomes-Alves S, Nicolás $\mathrm{M}$, Mata $\mathrm{M}$, Martínez AF, Borragán S, Anel E, de Paz $P$, 2008: Sperm cryopreservation in Brown Bear (Ursus arctos): preliminary aspects. Reprod Doc Anim 43(Suppl. 4), $1-9$.

Anel L, Gomes-Alves S, Álvarez M, Borragán $\mathrm{S}$, Anel E, Nicolás $\mathrm{M}$, MartinezPastor F, de Paz P, 2010: Effect of basic factors of extender composition on postthawing quality of brown bear electroejaculated spermatozoa. Theriogenology 74, 643-651.

Chaveiro A, Liu J, Engel B, Critser JK, Woelders H, 2006: Significant variability among bulls in the sperm membrane permeability for water and glycerol: possible implications for semen freezing protocols for individual males. Cryobiology 53, 349-359.

Curry MR, Watson PF, 1994: Osmotic effects on ram and human sperm membranes in relation to thawing injury. Cryobiology 31, 39-46.

Esteso MC, Fernandez-Santos MR, Soler AJ, Montoro V, Quintero-Moreno A, Garde JJ, 2006: The effects of cryopreservation on the morphometric dimensions of Iberian red deer (Cervus elaphus hispanicus) epididymal sperm heads. Reprod Domest Anim 41, 241-246.

Fernández-Santos MR, Esteso MC, Soler AJ, Montoro V, Garde JJ, 2006: Effects of egg yolk and cooling rate on the survival of refrigerated red deer (Cervus elaphus hispanicus) epididymal spermatozoa. Reprod Domest Anim 41, 114-118.

Gao D, Critser JK, 2000: Mechanisms of cryoinjury in living cells. ILAR J 41, 187196.

Gao DY, Liu J, Liu C, McGann LE, Watson PF, Kleinhans FW, Mazur P, Critser ES, Critser JK, 1995: Prevention of osmotic injury to human spermatozoa during addition and removal of glycerol. Hum Reprod 10, 1109-1122.

Hammadeh ME, Szarvasy D, Zeginiadou T, Rosenbaum P, Georg T, Schmidt W, 2001: Evaluation of cryoinjury of spermatozoa after slow (programmed biological freezer) or rapid (liquid nitrogen vapour) freeze-thawing techniques. J Assist Reprod Genet 18, 364-370.

Holt WV, 2000a: Basic aspects of frozen storage of semen. Anim Reprod Sci 62, 322.

Holt WV, 2000b: Fundamental aspects of sperm cryobiology: the importance of species and individual differences. Theriogenology 53, 47-58.

Holt WV, Lloyd RE, 2009: Artificial insemination for the propagation of CANDES: the reality! Theriogenology 71, 228-235.

Ishikawa A, Matsu M, Sakamoto H, Katagiri S, Takahashi Y, 2002: Cryopreservation of the semen collected by electroejaculation from the Hokkaido brown bear (Ursus arctos yesoensis). J Vet Med Sci 64, 373-376.

IUCN, 2008: IUCN red list of threatened species. Available: http://www.iucnred-

\section{6 list.org}

Loomis PR, Graham JK, 2008: Commercial semen freezing: individual male variation in cryosurvival and the response of stallion sperm to customized freezing protocols. Anim Reprod Sci 105, 119128

Martinez-Pastor F, Martinez F, GarciaMacias V, Esteso MC, Anel E, Fernandez-Santos MR, Soler AJ, de Paz P, Garde J, Anel L, 2006: A pilot study on post-thawing quality of Iberian red deer spermatozoa (epididymal and electroejaculated) depending on glycerol concentration and extender osmolality. Theriogenology 66, 1165-1172.

Muldrew K, 2008: The salting-in hypothesis of post-hypertonic lysis. Cryobiology 57, 251-256.
Nicolas M, Alvarez M, Gomes-Alves S, Mata-Campuzano M, Borragán S, Martinez-Pastor F, de Paz P, Anel L, 2011: Effects on brown bear (Ursus arctos) spermatozoa freezability of different extender and dilution ratios used for prefreezing centrifugation. Eur J Wildl Res 57, 259-266.

Okano T, Murase T, Tsubota T, 2004: Electroejaculation and semen cryopreservation of free-ranging japanese black bears (Ursus thibetanus japonicus). J Vet Med Sci 66, 1371-1376.

Okano T, Murase T, Yayota C, Komatsu T, Miyazawa K, Asano M, Tsubota T, 2006a: Characteristics of captive Japanese black bears (Ursus thibetanus japonicus) semen collected by electroejaculation with different voltages for stimulation and frozen-thawed under different conditions. Anim Reprod Sci 95, 134-143.

Okano T, Nakamura S, Komatsu T, Murase T, Miyazawa K, Asano M, Tsubota T, 2006b: Characteristics of frozenthawed spermatozoa cryopreserved with different concentrations of glycerol in Captive Japanese black bears (Ursus thibetanus japonicus). J Vet Med Sci 68, 1101-1104.

Pegg DE, 2002: The history and principles of cryopreservation. Semin Reprod Med 20, 5-13.

Perez-Garnelo SS, Garde J, Pintado B, Borque C, Talavera C, Delclaux M, Lopez M, Martinez JD, 2004: Characteristics and in vitro fertilizing ability of giant panda (Ailuropoda melanoleuca) frozenthawed epididymal spermatozoa obtained 4 hours postmortem: a case report. Zoo Biol 23, 279-285.

Province CA, Amann RP, Pickett BW, Squires EL, 1984: Extenders for preservation of canine and equine spermatozoa at $5^{\circ} \mathrm{C}$. Theriogenology 22, 409-415.

Pukazhenthi B, Santymire R, Crosier A, Howard J, Wildt DE, 2007: Challenges in 
cryopreserving endangered mammal spermatozoa: morphology and the value of acrosomal integrity as markers of cryosurvival. Soc Reprod Fertil Suppl 65, 433-446.

Spindler RE, Huang Y, Howard JG, Wang P, Zhang H, Zhang G, Wildt DE, 2004: Acrosomal integrity and capacitation are not influenced by sperm cryopreservation in the giant panda. Reproduction 127, 547-556.

Verstegen J, Iguer-Ouada M, Onclin K, 2002: Computed assisted semen analyzers in andrology research and veterinary practice. Theriogenology 57, 149-179.
Watson PF, 1990: Artificial insemination and the preservation of semen. In: Lamming GE (ed.), Marshall's Physiology of Reproduction, 4th edn, Vol II. Churchill Livingstone, London, pp. 747-869.

Woelders H, Matthijs A, Engel B, 1997: Effects of trehalose and sucrose, osmolality of the freezing medium, and cooling rate on viability and intactness of bull sperm after freezing and thawing. Cryobiology 35, 93-105.

Woods EJ, Benson JD, Agca Y, Critser JK, 2004: Fundamental cryobiology of reproductive cells and tissues. Cryobiology 48, 146-156.
Zee YP, Holt WV, Nicolson V, Pyne M, Johnston SD, 2009: Individual variability in post-thaw sperm survival in a captive koala population. Cryobiology 59, 69-74.

Submitted: 22 Feb 2011; Accepted: 21 Apr 2011

Author's address (for correspondence): $\mathrm{P}$ de Paz, ITRA-ULE, INDEGSAL, University of León, 24071, León, Spain. E-mail ppazc@unileon.es 